\title{
Redes de empresas e cooperação na formação do condomínio Tech Town
}

\section{Enterprise networks and cooperation in the formation of a Tech Town condominium}

\author{
Ricardo Furtado Rodrigues ${ }^{1}$ \\ Nelson Casarotto Filho' \\ Renata Lèbre La Rovere ${ }^{3}$
}

\begin{abstract}
Resumo: $\mathrm{O}$ artigo apresenta uma pesquisa cujo objetivo foi o de compreender as relações de cooperação existentes em redes de empresas, por meio do estudo do caso do Condomínio Tech Town, localizado no município de Hortolândia, região metropolitana de Campinas, SP. Numa abordagem geral o estudo destaca os principais desafios e oportunidades para o desenvolvimento de um polo produtor de software e serviços globais dentro do contexto de redes. Como resultado, observou-se que, apesar de este Condomínio ter sido criado com o objetivo de desenvolver um polo de alta tecnologia, suas principais empresas estão inseridas em redes globais e pouco contribuem para o desenvolvimento de processos de aprendizado e de inovação das empresas da região.
\end{abstract}

Palavras-chave: Redes de empresas. Cooperação. Tecnopolos.

\begin{abstract}
This paper presents a case study with the objective of understanding the cooperative relationship between the enterprise networks in the Tech Town Condominium, located in the municipality of Hortolândia, which belongs to metropolitan region of Campinas, Brazil. This study focuses on the main challenges and opportunities for the development of a major software producer and services provider center based on the global network concept. The results point to the fact that although the condominium was created with the goal to form a technopole, its enterprises are part of global networks and do not effectively contribute to learning and innovation processes of local enterprises.
\end{abstract}

Keywords: Networks. Cooperation. Technopole.

\section{Introdução}

A relação entre inovação e espaço territorial pode ser compreendida pela especificidade de ativos locacionais ou geográficos. Essa relação está na capacidade de reunir numa única localidade um conjunto de organizações (empresas e instituições) cujas atividades resultam na elaboração de novos produtos, novos processos produtivos e novas formas de organização da produção. Assim, o estabelecimento de laços de cooperação pode ser entendido como o primeiro passo para a atuação das empresas em rede, possibilitando a articulação e a integridade do sistema local de inovação aproveitando ao máximo as especificidade dos ativos com o objetivo de reduzir custos de transação.
A formação de parcerias ou cooperação é fundamental, sobretudo para as pequenas empresas localizadas no território, pois permite superar alguns obstáculos relacionados ao seu tamanho reduzido. Entretanto, muitas empresas pequenas não têm a cultura da cooperação, uma vez que os proprietários/ gerentes tendem a realizar um planejamento de curto prazo que os impede de perceber os benefícios da cooperação. Para muitos proprietários/gerentes, não é possível cooperar com os concorrentes. As empresas mais dinâmicas, porém, costumam superar esta dicotomia quando percebem que os laços de cooperação permitem a obtenção de benefícios ligados a externalidades positivas (LA ROVERE;

\footnotetext{
${ }^{1}$ Instituto Federal de Educação, Ciência e Tecnologia do Espírito Santo - IFES, Programa de Pós-graduação em Engenharia de Produção, Centro Tecnológico, Universidade Federal de Santa Catarina - UFSC, CP 476, Trindade, CEP 88040-900, Florianópolis, SC, Brasil, e-mail: ricardo.eng.ufsc@gmail.com

2 Programa de Pós-graduação em Engenharia de Produção, Centro Tecnológico, Universidade Federal de Santa Catarina - UFSC, CP 476, Trindade, CEP 88040-900, Florianópolis, SC, Brasil, e-mail:casarotto@ deps.ufsc.br

${ }^{3}$ Programa de Pós-graduação em Políticas Públicas, Estratégias e Desenvolvimento - PPED, Instituto de Economia, Universidade Federal do Rio de Janeiro - UFRJ, Campus da Praia Vermelha, Av. Pasteur, 250, Urca, CEP 22290-240, Rio de Janeiro, RJ, Brasil; e-mail: renataieufrj@gmail.com
} 
CARVALHO, 2004). Tendo como foco as redes de empresas formadas em condomínios tecnológicos, teriam essas empresas condições para estabelecer relações de cooperação? E o condomínio, enquanto gestor de uma rede, facilitaria o relacionamento entre as empresas? Essas são as questões a serem respondidas neste artigo.

Nesse contexto, o objetivo do artigo foi realizar um estudo sobre as relações de cooperação em redes de empresas, tomando como estudo de caso a rede do Condomínio Tech Town, localizado no município de Hortolândia, que faz parte da região metropolitana de Campinas, SP. O Condomínio, constituído por uma iniciativa conjunta da prefeitura de Hortolândia com a IBM, tem como objetivo principal atrair para este município empresas de alta tecnologia. Num contexto geral, destacar-se-ão os principais desafios e oportunidades para o desenvolvimento de um polo de Tecnologia da Informação e Comunicação (TIC) e serviços globais dentro do contexto de redes. Foram examinados também os diferentes papéis exercidos pelas empresas locais e globais no mercado e suas estratégias de crescimento e competitividade, visando posicionar o papel dos atores no processo de desenvolvimento.

Entre os procedimentos metodológicos, além do fato de tratar-se de um estudo de caso, elaborou-se um estudo analítico e bibliográfico sobre o município de Hortolândia e Condomínio Tech Town, e foi realizada uma série de entrevistas com diretores das principais empresas instaladas no polo tecnológico e com representantes do governo local.

A questão que motivou o desenvolvimento da pesquisa que fundamenta este artigo foi identificar se a proximidade geográfica das empresas no Condomínio facilitou o estabelecimento de laços de cooperação ou se, no caso destas empresas, o que prevaleceu foi a inserção em redes globais, ou seja, a proximidade organizacional. Como questão associada, buscou-se investigar se a atuação destas empresas na região de Campinas, que se caracteriza pela presença de diversas universidades e centros de pesquisa, favoreceu o desenvolvimento de processos de aprendizado por parte das empresas locais.

\section{Metodologia da pesquisa}

Por se tratar de um tema pouco explorado no Brasil, a revisão de literatura realizada para a pesquisa se baseou na discussão sobre os ganhos relacionados à proximidade geográfica e organizacional nas empresas e sobre a organização de redes globais no setor de TIC. Entre os estudos analisados, vários apontam para o papel dos órgãos públicos e instituições na promoção de ações e políticas de apoio ao desenvolvimento da competitividade das empresas em aglomerações territoriais de empresas (SUZIGAN et al., 2006). Outros estudos também separam os ganhos advindos de iniciativas de formação de redes territoriais de empresas em vantagens estáticas, tais como a proximidade de grandes mercados e infraestrutura, ou dinâmicas, tais como possibilidades de interação com universidades e desenvolvimento de inovações (NADVI; SCHMITZ, 1994).

A pesquisa teve assim caráter exploratório, com três objetivos principais. Em primeiro lugar, investigar se o Condomínio de empresas Tech Town permitiu laços de cooperação entre as empresas devido à proximidade geográfica. Em segundo lugar, analisar de que forma estas empresas estabelecem relações com as instituições de ensino e pesquisa locais. Em terceiro lugar, levantar informações sobre as redes globais nas quais as empresas se inserem. Assim, a pesquisa pretendeu investigar o papel da proximidade geográfica e da proximidade organizacional para as empresas sediadas no Condomínio. Buscou-se também investigar se as empresas foram atraídas para a região movidas por vantagens estáticas ou dinâmicas.

Além da revisão de literatura e do levantamento de informações sobre o município de Hortolândia e Condomínio Tech Town, foram identificadas as empresas mais importantes do Condomínio, a saber: IBM, DELL, Celéstica e Comsat. Foi então realizada uma série de entrevistas com diretores destas empresas e com representantes do governo local. Optamos por não incluir a DELL no painel de entrevistados, uma vez que esta empresa chegou ao Condomínio num momento posterior às demais e preservou o centro das suas operações no Brasil na filial da empresa de Porto Alegre. As entrevistas com as empresas buscaram mapear as fontes de informação para o desenvolvimento de inovações utilizadas pelas empresas, identificar o papel das relações de cooperação no desenvolvimento de inovações e identificar os principais motivos de localização das empresas na região.

A pergunta sobre fontes de informação para o desenvolvimento de inovações utilizadas para as empresas incluiu tanto fontes externas quanto fontes internas. Como fontes externas, foram consideradas experiências anteriores da equipe, sugestões dos empregados e presença de departamento de pesquisa e desenvolvimento. Como fontes externas, foram consideradas consultorias, publicações especializadas, patentes, aquisição de novos equipamentos, congressos e parcerias com universidades e centros tecnológicos.

A pergunta sobre o papel das relações de cooperação para o desenvolvimento de inovações nas empresas listou as seguintes relações de cooperação: com fornecedores de equipamentos, com empresas de manutenção, com clientes, com outras empresas e com instituições de ensino.

A pergunta sobre as vantagens da localização no local listou as principais vantagens resultantes da localização no Condomínio Tech Town, a saber: 
infraestrutura física disponível, infraestrutura de serviços disponível, proximidade com universidades e centros de pesquisa, disponibilidade de mão de obra, incentivos fiscais, proximidade com fornecedores, proximidade com o mercado e facilidades de comunicação e transporte.

Assim, o artigo pretende contribuir para o debate sobre a diversidade das formas de redes de empresas concentradas espacialmente e suas implicações para a formulação de políticas de atração de empresas de alta tecnologia para uma região.

\section{Redes de empresas e cooperação}

O cenário atual de globalização e a rápida mudança tecnológica do período recente fazem com que as empresas busquem parcerias, adquirindo vantagens competitivas associadas ao novo paradigma científicotecnológico. Obviamente, esse ambiente suscita a colaboração entre as empresas e as instituições científicas e tecnológicas, criando os meios mais favoráveis para isso em forma de redes e associações.

Segundo Garcia et al. (2010), este novo cenário globalizado da economia reflete a transição da eficiência individual para a eficiência coletiva de empresas. Ou seja, a competitividade das empresas, cada vez mais, relaciona-se ao desempenho de redes interorganizacionais e não de empresas isoladas.

Para Casarotto Filho e Pires (2001), estabelecer parcerias para trabalhar de forma associada entre empresas ou estabelecer uma rede de cooperação entre pequenas e médias empresas é uma forma de se tornarem mais ágeis e flexíveis nos seus processos e serem tão competitivas como as grandes empresas. Para os autores, essa associação entre empresas pode se dar por dois tipos de redes, são elas:

- Redes topdown, na qual as pequenas empresas podem tornar-se fornecedoras de uma grande empresa, produzindo parte de seu produto com o objetivo final de competirem por liderança de custos. Neste caso, as pequenas empresas são dependentes das estratégias da empresa âncora e não têm poder de influência sobre a rede;

- Redes flexíveis, em que cada empresa contribui com uma parte do produto, que é comercializado, divulgado e assistido tecnicamente, e todas são responsáveis pelo resultado. Neste caso, situam-se os consórcios que promovem competitividade internacional a empresas que sozinhas não alcançariam vantagem competitiva.

Essa rede de relações entre empresas desencadeia o aprendizado e melhora a habilidade dos atores para modificar seu comportamento e encontrar novas soluções em resposta às mudanças competitivas (PORTER; SOLVELL, 1998 apud SUZIGAN et al., 2006).
O fortalecimento das redes de empresas além de gerar competitividade local propicia às empresas um salto qualitativo em termos de sua inserção internacional, promove resultados favoráveis para todas as empresas do aglomerado produtivo e possibilita o acesso a tecnologias diferenciadas, criando um ciclo virtuoso de desenvolvimento da região (MAIS et al., 2010).

O desenvolvimento de uma determinada região vai depender de como a rede se articula para gerar novas ideias, difundir e utilizar inovações que realmente tenham valor econômico para o mercado (YAM et al., 2011). A inovação não é apenas determinada por fatores internos isolados a uma única empresa, mas também por um processo interativo envolvendo o relacionamento entre todas as empresas da rede. As empresas não podem inovar de forma isolada, pois elas tendem a complementar a sua capacidade de criar conhecimento dentro da rede por meio de parcerias e utilizando conhecimento a partir de fontes externas de inovação por meio também de cooperação (LENGRAND; CHATRIE, 1999; FORAY, 2000).

A parceria pode se realizar tanto com empresas locais quanto com empresas situadas fora do território. No caso do software, a importância das relações locais de parceria pode ser entendida a partir da constatação de que, para as firmas cujo desenvolvimento é baseado em conhecimento científico, estar próximo de centros de pesquisa acadêmica de alta qualidade pode ser uma vantagem. No momento de criação de uma firma, a localização em um ambiente científico dinâmico é essencial, mesmo que, com seu crescimento, a importância da proximidade geográfica diminua (MORGAN, 2001 apud AMIN; COHENDET, 2005). A proximidade geográfica, por proporcionar maior contato entre as firmas, significa fluência do conhecimento naquele local, circulação de ideias e de know-how, além do aumento do último graças à especialização e à união dos trabalhadores (MORGAN, 2001 apud AMIN; COHENDET, 2005).

A parceria deve ser entendida como um conjunto de procedimentos e ações de respeito mútuo e convergência de interesse entre instituições, ou entre unidades de uma mesma instituição. As partes envolvidas não têm supremacia entre si. A parceria se caracteriza, consequentemente, por uma ação entre iguais. A igualdade independe do tamanho da organização ou de sua posição financeira. Prevalece, nesse caso, o comprometimento institucional com objetivos comuns e a flexibilidade para responder às demandas apresentadas pelos parceiros. Há na parceria, a utilização compartilhada de recursos humanos, financeiros e físicos (RODRIGUES; BARBIERO, 2002). Dentro destes recursos compartilhados está o conhecimento codificado, que pode ser deslocado de seu ambiente original e ser utilizado em qualquer outro 
lugar, e o conhecimento tácito, que é "[...] dependente do contexto e socialmente acessível apenas através de interação física direta [...]" (MORGAN, 2001 apud AMIN, 2005, p. 468). Os processos de aprendizado podem ser facilitados entre empresários, numa rede concentrada espacialmente, pela proximidade geográfica. Isto porque as firmas localizadas no mesmo ambiente têm a possibilidade de monitorar, comparar, selecionar e imitar as soluções "do vizinho" para problemas similares.

Relações de parceria é a base para o estabelecimento de laços de cooperação. Estes laços se constituem numa condição necessária, porém não suficiente para o desenvolvimento de redes de empresas num território. Isto porque há outra dimensão inerente às relações entre as empresas que irá condicionar a arquitetura da rede, a saber as relações de hierarquia (GAROFOLI, 1993). Uma rede de empresas não hierarquizada $e$ concentrada espacialmente irá desenvolver formas de cooperação horizontal, em que as empresas dividem tarefas ao longo da cadeia produtiva ou então dividem lotes de produção. Este é o caso dos chamados distritos industriais marshallianos. Uma rede de empresas hierarquizada e concentrada espacialmente irá desenvolver outro tipo de laços de cooperação, em que as empresas do território prestam serviços à empresa que é o centro da rede. Markusen (1996) chamou esta estrutura de distrito centro-radial; neste tipo de distrito, apesar de haver geração de externalidades positivas ligadas à especificidade dos ativos, as possibilidades de desenvolvimento de inovações por parte de empresas pequenas serão reduzidas, uma vez que sua capacitação se desenvolve para atender às necessidades de outra empresa, e não do mercado.

No caso das tecnologias de informação e de comunicação (TIC), existe ainda outro elemento para qualificar o debate sobre o desenvolvimento de uma rede de empresas. Nesta indústria, há outro tipo de proximidade relevante para o desenvolvimento de laços de cooperação, uma vez que o produto é imaterial e pode ser transmitido rapidamente de um país a outro. Podem surgir então laços de cooperação de empresas situadas em territórios distantes, movidas por interesses comuns, caracterizando o que diversos autores chamam de proximidade relacional ou organizacional (AMIN; COHENDET, 2005).

Cabe aqui ressaltar que o conceito de redes concentradas espacialmente é apenas um entre os vários conceitos que podem ser utilizados para entender o fenômeno das aglomerações territoriais de empresas. Os estudiosos deste fenômeno propõem diversos conceitos, como distritos industriais (PYKE; BECCATINI; SENGERBERGER, 1990), cluster (NADVI; SCHMITZ, 1994, PORTER, 1998, BRESCHI; MALERBA, 2001), sistemas produtivos locais (POMMIER, 2002) e arranjos produtivos locais (CASSIOLATO; SZAPIRO, 2003). Estes conceitos são utilizados para analisar aglomerações territoriais e setoriais de empresas. Quando se trata de uma aglomeração de empresas de alta tecnologia que têm relação com universidades e centros de pesquisa locais, é proposto o conceito de polo tecnológico. Quando este polo se constitui a partir de uma iniciativa de instituições nacionais ou locais, é proposto o conceito de parque tecnológico ou Science Park (ASSOCIAÇÃO..., 2006; HANSSON, 2004; SQUICCIARINI, 2009).

As diferenças entre os diversos conceitos se relacionam, em primeiro lugar, com o próprio objeto de estudo: enquanto os autores que trabalham com o conceito de cluster se centram mais na análise das empresas, os autores que trabalham com tecnopolos e parques tecnológicos focam também o papel das instituições ligadas à geração de conhecimento, como incubadoras e universidades. Já os autores que trabalham com distritos industriais e com sistemas e arranjos produtivos locais levam em consideração, além de empresas e universidades, instituições locais de apoio como associações empresariais e bancos de fomento.

Em segundo lugar, há diferenças entre os autores quanto ao papel atribuído às vantagens da aglomeração. As vantagens da aglomeração podem ser divididas em dois grupos principais. O primeiro grupo são as vantagens estáticas ou ligadas à produção, como vantagens pecuniárias advindas de consórcios de compras ou vantagens ligadas à localização como compartilhamento de infraestrutura. $\mathrm{O}$ segundo grupo são as vantagens dinâmicas ou tecnológicas, ligadas às possibilidades de compartilhamento de informações e conhecimento, que leva ao desenvolvimento de inovações. Enquanto alguns autores que trabalham com o conceito de cluster entendem que a aglomeração propicia vantagens estáticas e dinâmicas, outros autores, como Malmberg e Power (2005), alertam que nem sempre é possível verificar empiricamente a presença de vantagens dinâmicas relacionadas à aglomeração em clusters. Squicciarini (2009) e Hansson (2004) fazem a mesma observação em relação aos parques tecnológicos.

É importante chamar a atenção para a diversidade de casos em redes concentradas espacialmente para qualificar o debate sobre os seus benefícios para uma região. Diversas políticas de apoio na Europa e no Brasil parecem partir do pressuposto de que a formação de redes de empresas concentradas espacialmente será positiva para o desenvolvimento regional, à medida que as relações de cooperação entre as firmas permitem a geração de aprendizado local e o desenvolvimento de inovações. Entretanto, nem sempre estes resultados positivos se concretizam (LA ROVERE; SHEHATA, 2006; MARTIN; SUNLEY 2003). Como observado por Lastres, Arroio e Lemos (2003), isso frequentemente 
ocorre devido à inadequação das políticas para o desenvolvimento de micro e pequenas empresas locais. Breschi e Malerba (2001) ressaltam que os clusters não são fenômenos de fácil replicabilidade, portanto é necessário analisar experiências concretas de atração de empresas de alta tecnologia para determinados territórios para avaliar se de fato estas empresas contribuem para a geração de conhecimento local.

Condomínios tecnológicos são sistemas que comportam empresas de base tecnológicas, e sua gestão pode oferecer serviços e promover a cooperação em diversas etapas da cadeia de valor das empresas (BITTENCOURT, 2008). Ainda segundo Bittencourt (2008), alguns componentes favorecem o surgimento e o desenvolvimento de parques e polos tecnológicos: a existência de instituições de ensino e pesquisa; uma aglomeração de empresas de base tecnológica; a ocorrência de projetos envolvendo empresas e universidades; e uma estrutura organizacional mínima que promova a governança da rede.

Assim sendo, aproveitar as diversas fontes de tecnologia externa às empresas por meio de acordos de parcerias e cooperação entre empresas, instituições de fomento e universidades pode ser um fator competitivo que, além de estimular a capacidade de inovação das empresas de software, pode minimizar custos e maximizar os recursos físicos existentes. Além disso, um dos fatores decisivos para a formalização e consolidação das parcerias e apoio tecnológicos para empresas de software reside nas bases de confiança e interesses comuns entre os empresários e suas estratégias de negócios. A formalização de um condomínio tecnológico pode acelerar esse processo de cooperação e fortalecimento das bases de confiança

Portanto, os benefícios das interações na rede vão depender da confiança, dos valores e de como o conhecimento é compartilhado e utilizado entre as empresas para desenvolver novos produtos, processos e outras inovações.

\section{$4 \mathrm{O}$ caso estudado: Surgimento do Condomínio Tech Town como polo de TIC}

A ideia do condomínio surgiu em função da globalização dos mercados e a estruturação das empresas que vem acontecendo a partir dos anos 1990. Antes as empresas tinham um foco voltado para a manufatura, que é o caso da IBM, e hoje o foco está na realização de serviços a partir da terceirização. Logo o Condomínio Tech Town surge como um aglomerado de empresas, tendo a IBM como principal empresa.

O Condomínio Tech Town foi criado no município de Hortolândia no ano de 2001 a partir de uma iniciativa da IBM juntamente com o governo local. No início, eram 20 empresas de tecnologia que tiveram como apoio a própria IBM. O Condomínio surgiu em resposta às necessidades de um mercado competitivo e industrial globalizado, e que fez do município um grande polo de TIC e serviços. Segundo Mendes (2011), o Tech Town foi pensado como um condomínio empresarial-tecnológico, e as construções foram feitas sob medida para a locação, de acordo com as necessidades das empresas, sendo assim "um espaço integrado e inteligente” (MENDES, 2011, p. 7).

A sua localização pode ser considerada estratégica por estar às margens do prolongamento da Rodovia dos Bandeirantes, uma posição extremamente privilegiada dentro da ampla malha viária existente na região, além da proximidade com o Aeroporto Internacional de Viracopos. Outro aspecto importante que atraiu as empresas de TI para o condomínio foi o incentivo fiscal oferecido pelo município.

Entre as empresas que compõem o Condomínio, três delas foram selecionadas para a pesquisa de campo devido à sua importância, a saber: o Centro de Tecnologia da IBM, um dos quatro centros globais de serviços de TIC da companhia; a Celéstica, fabricante de componentes para indústrias de informática e telecomunicações; e a Comsat Internacional, que oferece soluções em telecomunicações.

De acordo com o secretário municipal de Planejamento Urbano e Desenvolvimento, Hortolândia é conhecida pelo forte potencial em tecnologia desde a chegada da IBM, e mais recentemente da DELL, no entanto a grande importância desse potencial e do desenvolvimento econômico se dá em função da diversidade de empresas na região. Ainda segundo o secretário, os três setores da indústria que alavancam a economia hortolandense são a de eletroeletrônicos, indústria automobilística e a construção civil. A cidade sempre teve crescimentos na indústria local, até porque o município não possui vocação agrícola por ter um território muito pequeno.

\section{Características das principais empresas do Condomínio Tech Town}

Na sequência, são apresentadas as empresas pesquisadas, com algumas informações históricas e técnicas, e os motivos que as levaram a se instalar no Condomínio.

\section{a. IBM}

Atualmente a empresa está presente em 170 países, com aproximadamente 355 mil funcionários em todo o mundo, e no município de Hortolândia a empresa concentra 7 mil funcionários. Sua renda está em torno de US \$ 100 bilhões, sendo que $60 \%$ provêm de operações fora dos EUA, e deste montante US $\$ 6$ bilhões são investidos em pesquisa e desenvolvimento. 
Uma das estratégias da IBM é investir pesado no setor de serviços de TIC, e é claro, um reflexo da constante evolução tecnológica dos anos 1990, pois, até 1995 , a empresa prestava serviços de apoio às empresas que estavam se informatizando ou em fase de implantar seus sistemas. No sentido de consolidar sua posição neste mercado, a IBM, em parceria com a Gerdau, criou a GSI - Gerdau Serviços de Informática, iniciando, assim, a formação da cultura de outsourcing no Brasil. E, no final da década de 1990, a GSI assinou seu primeiro contrato de outsourcing com o Chase Manhatan Bank (INTERNATIONAL..., 2009).

Um pouco antes, no ano de 1994, os três centros de processamento de dados (São Paulo, Hortolândia e Rio de Janeiro) foram consolidados em Hortolândia, dando origem ao megacentro de serviços de outsourcing. Mas foi em 1996, que a IBM mundial definiu a estratégia de criar centros de serviços de outsourcing em cada região e concentrou em Hortolândia todas as atividades dos centros de processamentos de dados da América Latina.

E hoje, uma das mais importantes unidades da IBM é o Centro de Tecnologia de Hortolândia, que está interligado com todos os outros megacentros de processamento da IBM no mundo. Sua estrutura é constituída por quatro grandes segmentos, sendo eles: Serviços de Outsourcing; Desenvolvimento e Manutenção de Aplicativos (Software Factory); Serviços de BPO; e o Américas Delivery Center, que é responsável pelo monitoramento de todas as unidades da IBM nas Américas.

É também nesse centro que está concentrada toda a infraestrutura de TIC necessária para dar suporte aos clientes que decidiram terceirizar suas operações e processos de TIC para melhor focar em seus negócios.

Foi inaugurado também em 19 de agosto de 2005 o Global Command Center - a 'torre de comando' de todas as operações de serviços de outsourcing que a IBM Brasil presta para mais de 50 clientes instalados no País e em diversas partes do mundo.

De acordo com o vice-presidente de Serviços da IBM Brasil, a operação do novo Global Command Center foi um marco para a prestação de Serviços da IBM Brasil. Segundo ele, com esta unidade, a IBM pode oferecer aos seus clientes uma operação de gerenciamento e monitoramento de seu ambiente de TIC ainda mais eficaz, atendendo às necessidades e flexibilidades que seus negócios demandam, independente de sua localização geográfica.

\section{b. A DELL em Hortolândia}

Os principais atrativos que levaram a DELL a instalar uma fábrica no município de Hortolândia são a política industrial local; o fato de a cidade estar perto dos grandes centros consumidores do Sudeste, em especial São Paulo; a infraestrutura de qualidade; boa oferta de profissionais qualificados nas cidades do entorno; proximidade em relação aos fornecedores e clientes; e pela facilidade de acesso às rodovias e principais aeroportos da região (SIMÕES, 2006).

Antes, centralizada em Eldorado do Sul (RS), a DELL atendia aos mercados no Brasil, Chile, Argentina, Colômbia e África do Sul. Com a nova fábrica em Hortolândia, e as novas facilidades para exportação em função de o local ser estratégico, a empresa passa a ter ganhos em termos de redução no tempo de entrega e nos custos, aumentando assim, sua presença no mercado corporativo.

De acordo com o secretário municipal de Planejamento Urbano e Desenvolvimento, a empresa Dell foi atraída para Hortolândia visando ao aumento do PIB e dos empregos do município. Para o secretário, o PIB do município vem crescendo constantemente como resultado da concentração cada vez maior de empresas de alta tecnologia no município, processo que começou com a instalação da fábrica da IBM, em 1971.

Mas é importante ressaltar que o Centro de Desenvolvimento Global (CDG) da empresa, primeiro centro de P\&D da DELL instalado fora dos Estados Unidos, continuou no TECNOPUC, parque tecnológico da Pontifícia Universidade Católica do Rio Grande do Sul (PUCRS).

\section{c. Comsat International}

A Comsat foi criada na década de 1960, sendo a precursora na implantação de pontos de acesso à Internet (NAPs) na América do Sul. No Brasil, a empresa estabeleceu-se em 1994, mas somente após a aquisição de duas grandes empresas passou a ser líder em serviços de telecomunicações da América Latina.

As duas aquisições aconteceram em 2004, a primeira com a compra da GBNet da Convergence Communications, que incluía uma rede de operações no México e outros países da América Central. Com essa compra a Comsat agregou serviços de acesso à internet em banda larga e soluções de dados para a América Central. Em agosto do mesmo ano, a Comsat adquire a Vicom, provedora de serviços por satélite e circuitos de fibra óptica em áreas metropolitanas e que fazia parte do grupo NET Serviços de Comunicação S/A. Feito isso, a Comsat passou a ser então a líder em serviços de rede de comunicação via satélite na América Latina, atendendo a grandes programas de inclusão digital, governamentais e empresariais.

Segundo um dos especialistas em sistemas de gerência da Comsat, um grande marco para a empresa aconteceu quando a BT Global Services do Reino Unido comprou a Comsat e sua operação em mais de dez países da América Latina, inclusive no Brasil.

Já no Centro Tecnológico instalado no condomínio Tech Town de Hortolândia, a Comsat inaugurou um grande teleporto, um dos mais completos e o maior em diversidade de serviços do Brasil. O teleporto dispõe de acessos a vários satélites, além de interconexão com redes de fibras ópticas com conectividade 
internacional, sendo controlado por um Centro de Operações, no qual técnicos especializados trabalham 24 horas durante todo o ano.

Atualmente a Comsat de Hortolândia tem em torno de 300 funcionários, e sua chegada ao município aconteceu com a abertura do Condomínio pela própria IBM, que, segundo um dos especialistas em sistemas de gerência, foi uma oportunidade para a empresa, pois necessitava de área para sua instalação.

\section{d. Celéstica}

A criação da Celéstica ocorreu em 1996 a partir de um spin-off da IBM Canadá, por Investimento do grupo Onex. Hoje a empresa tem em torno de 40 mil funcionários distribuídos em 40 fábricas em 16 países, e seu faturamento no ano de 2002 atingiu US\$ 8 bilhões.

No Brasil, a empresa surgiu no ano de 1999 em Guarulhos e, em 2002, transferiu suas operações para o município de Jaguariúna. Já em 2005, a empresa que é fabricante de componentes para indústrias de informática e telecomunicações, mudou suas operações de Jaguariúna para o Condomínio Tech Town em Hortolândia, criando cerca de 300 empregos na nova sede.

O motivo da transferência se deu com o término do contrato com a Motorola de Jaguariúna, pois a Celéstica funcionava no condomínio da empresa e não fazia sentido continuar. Surgiram, também novas vantagens: a infraestrutura do Condomínio Tech Town disponibilizada pelo município de Hortolândia e a proximidade com o Aeroporto Internacional de Viracopos.

Apresentadas as empresas, elas serão então analisadas na próxima seção em relação às suas parcerias.

\section{Parceria e outsourcing entre as empresas e sua relação com as universidades}

Atualmente as empresas vêm respondendo a vários desafios colocados pela Nova Economia de diversas formas. Segundo Tigre et al. (2007) no caso da indústria de IT-enabled services (conjunto de serviços prestados a distância e que estão relacionados a atividades específicas da área de TI, seja de infraestrutura ou gestão e manutenção de aplicativos), uma forma que vem sendo praticada por grandes empresas é o outsourcing. $\mathrm{O}$ outsourcing representa uma prática em que parte do conjunto de produtos e serviços utilizados em uma empresa é realizada por outra empresa, num relacionamento colaborativo e interdependente. A empresa fornecedora se especializa e se desenvolve continuamente enquanto a outra empresa cliente se empenha nas suas atividades principais (PIRES, 2011; EULALIA; BREME; PIRES, 2011). Para esses autores o outsourcing significa, em sua essência, uma relação de parceria e cumplicidade com um ou mais fornecedores da cadeia produtiva, a partir de uma decisão estratégica, global e de difícil reversão.

Segundo Corbett (2011), grande parte das empresas hoje em dia está adotando outsourcing como base de seus esforços para alinhar-se ao enfoque de mercado, para capitalizar oportunidades globais e para fortalecer as operações. Para Corbett é interessante observar que ao mesmo tempo, organizações pequenas também estão adotando outsourcing como um modo de acompanhar a capacidade de uma grande organização, sem os custos e o tempo despendidos na aquisição e na administração direta de cada novo recurso.

A relação de parceria e colaboração em termos de apoio tecnológico pode ser obtida também pela relação entre empresas e instituições produtoras de conhecimento, como as universidades e/ou centros de pesquisa. Apesar de as universidades e as empresas terem papéis distintos na sociedade, elas podem ser complementares entre si. Ambas são agentes de inovação tecnológica porque fazem parte do sistema de inovação, cada qual com objetivos distintos, mas que podem colaborar com seus recursos disponíveis para o avanço do desenvolvimento científico e tecnológico.

Diante do exposto e a partir das entrevistas, será discutida a interação entre esses atores, porém sob uma perspectiva local, tomando em conta o contexto de desenvolvimento do Condomínio Tech Town.

\section{a. IBM}

A partir do processo de globalização dos mercados, a IBM tem se tornado uma empresa globalmente integrada não só no desenvolvimento de produto como o software, mas principalmente em serviços. E, como a empresa atua de forma global, é comum a troca de conhecimentos entre as empresas.

Em 971, foi inaugurada a fábrica de computadores em Hortolândia e, para atender às novas exigências do mercado, a empresa mudou o foco, deixando de ser predominantemente de fabricação e passou a ser uma organização prestadora de serviços. Hoje essa localidade é o maior Global Delivery Center da América Latina, ou seja, $90 \%$ das operações são serviços.

De acordo com o Diretor do Centro de Tecnologia da IBM, dentro desse contexto de Global Delivery Center, a empresa tem uma série de serviços que iniciam no município, e os principais pontos são o governo, o centro de terceirização, que envolve o outsourcing principalmente, infraestrutura de tecnologias e desenvolvimento e manutenção de aplicações e processos. Basicamente a empresa é organizada por essas linhas de serviços de competências dentro do contexto de outsourcing e tecnologia.

As entrevistas revelaram que as principais fontes de informação e conhecimentos especializados utilizados pela empresa são tanto internas quanto externas. As 
fontes internas mencionadas foram experiências anteriores da equipe, sugestões dos empregados e do departamento de pesquisa e desenvolvimento, enquanto que as fontes externas mencionadas foram consultorias, publicações especializadas, patentes, aquisição de novos equipamentos, congressos e parcerias com universidades e centros tecnológicos. No que se refere às formas de cooperação enquanto fonte de inovação para a empresa, a IBM considerou importantes todas as formas citadas, a saber: cooperação com fornecedores, com empresas de manutenção, com clientes, com outras empresas e com instituições de ensino e de pesquisa.

No que se refere a benefícios para empresas e instituições de ensino e pesquisa locais, resultantes de laços de cooperação, cabe ressaltar que as principais parcerias da IBM com atores locais são parcerias com universidades. A empresa constituiu em 2003, em parceria com a UNICAMP, um centro de desenvolvimento de software com plataforma Linux, que, desde então, gerou diversas patentes. A empresa promove também diversos cursos de capacitação, tanto na UNICAMP quanto em outras universidades de São Paulo. Egressos destas universidades podem até criar suas próprias empresas em função da capacitação recebida, como sugerido pela literatura a respeito de benefícios da cooperação entre universidades e empresas. Porém, o que foi constatado na nossa pesquisa é que a maioria dos estudantes que participam de ações de capacitação opta por ir trabalhar na própria IBM ou em empresas do setor de TIC da região.

Já as parcerias com empresas locais se inserem num contexto mais amplo de ações de responsabilidade social da empresa. Para o Diretor do Centro de Tecnologia, a IBM tem uma relação estreita com o município de Hortolândia, não só com o governo, mas com a sociedade no que tange a questões comunitárias, como é o caso do programa de voluntariado dos funcionários da IBM e do laboratório de informática da UNICAMP construído em parceria com a IBM e destinado a treinamento em informática de membros da comunidade. Esses programas têm como objetivo ajudar as empresas menores, até porque muitas das pequenas empresas de tecnologia são fornecedoras, seja na área de infraestrutura e locação de mão de obra ou venda de serviços. As demais empresas que não atuam na mesma cadeia produtiva são beneficiadas por programas de qualificação e treinamento oferecidos no município.

Finalmente, a IBM considerou importantes todas as vantagens de localização mencionadas no roteiro de entrevistas, a saber: infraestrutura física disponível; infraestrutura de serviços disponível; proximidade com universidades e centros de pesquisa; disponibilidade de mão de obra; incentivos fiscais; proximidade com fornecedores; proximidade com o mercado; e facilidades de comunicação e transporte. A disponibilidade de mão de obra apareceu na fala dos entrevistados como sendo fundamental: de acordo com um deles, "a IBM emprega 7.000 pessoas (da região) e empregaria mais se pudesse".

Assim, os benefícios de relações de cooperação enquanto mobilizadoras de inovação em empresas locais parceiras parecem não se verificar no caso da IBM. Isto ocorre em função da situação da IBM enquanto empresa global. Como visto anteriormente, ela realiza diversas atividades de outsourcing, e grande parte da administração de contratos e do suporte técnico com a IBM América e com outras localidades, que vão desde o Alasca até a Patagônia, é feita pelo Centro de Tecnologia de Hortolândia. Isso acaba por gerar uma grande demanda da IBM por pessoal qualificado com habilidade em vários idiomas, por isso o interesse da empresa de capacitar profissionais na região. Este interesse leva a empresa a priorizar parcerias com universidades locais que geram processos de aprendizado, os quais ficam, porém, circunscritos às instituições de pesquisa e ensino locais.

\section{b. Comsat}

A empresa vem buscando se adequar ao processo de globalização econômica por meio de melhorias nos equipamentos em função da evolução da tecnologia, garantindo certificado para áreas técnicas e com a qualidade dos serviços, o que tem gerado rendimentos crescentes no faturamento da empresa.

Em relação a associações e alianças estratégicas, a empresa tem formado mais alianças com os fornecedores de equipamentos e de soluções para o provimento de serviços. De acordo com o Especialista de Sistemas em Gerência da empresa, o cliente não está preocupado com o tipo de infraestrutura da empresa e sim com o serviço que ele demanda, então faz-se necessário ter parcerias fortes, relacionamentos e alianças firmes. O parceiro é considerado muito importante pela empresa porque ele provê a tecnologia necessária para manter a rede e os serviços a serem prestados aos clientes. Além disso, é necessário para que a empresa tenha competitividade e qualidade.

$\mathrm{Na}$ área de trabalho e capacitação, a Comsat realiza treinamentos em todas as áreas. Cada área tem um planejamento para definir suas prioridades, e, a partir disso, são realizados os treinamentos para atender a suas demandas específicas.

A pesquisa e aprendizado são desenvolvidos nos laboratórios de engenharia, mas é mais no sentido de desenvolver uma adequação a tecnologias existentes do que propriamente de pesquisa, até porque a finalidade não é gerar um novo produto e sim novas formas de utilização e aproveitamento de tecnologias de parceiros. Antigamente existia mais pesquisa na área de desenvolvimento de satélites da empresa e a principal razão de esta não ter mais uma atividade de pesquisa forte foi justificada nas entrevistas como resultante da situação do próprio mercado de 
telecomunicações. Segundo o entrevistado, existe muita competição por preço e produtos já existentes no mercado, o que de certo modo acaba inviabilizando a pesquisa na empresa, pois a tecnologia já consolidada traz os resultados necessários, além de proporcionar menores custos na entrega.

As entrevistas revelaram que a empresa prioriza suas fontes internas na aquisição de informações e conhecimento especializado, em particular a equipe e sugestões dos empregados (ver Quadro 1).

As fontes advindas do Departamento de Pesquisa e Desenvolvimento não foram consideradas importantes porque o desenvolvimento de pesquisas nesta filial da empresa foi forte no passado quando desenvolvia investigações e testes na área de satélites.

No entanto, as consultorias e troca de informações com empresas fornecedoras tornaram-se grandes fontes de aquisição de conhecimentos especializados em função da relação direta com os clientes e fornecedores. A importância dessa integração com outras empresas tem contribuído para novas formas de desenvolvimento e incorporação de novas tecnologias conforme mostrado no Quadro 2.

Quadro 1. Principais fontes de informação/conhecimentos especializados utilizados pela empresa.

\begin{tabular}{|l|c|c|}
\hline \multicolumn{1}{|c|}{ Origem } & Sim & Não \\
\hline Experiências anteriores da equipe & $\mathrm{X}$ & \\
\hline $\begin{array}{l}\text { Departamento de Pesquisa e } \\
\text { Desenvolvimento (P\&D) }\end{array}$ & $\mathrm{X}$ \\
\hline Consultorias especializadas & $\mathrm{X}$ & \\
\hline Universidades e Centros Tecnológicos & & $\mathrm{X}$ \\
\hline $\begin{array}{l}\text { Publicações especializadas/Catálogos } \\
\text { técnicos }\end{array}$ & $\mathrm{X}$ & \\
\hline Patentes & & $\mathrm{X}$ \\
\hline Aquisição de novos equipamentos & $\mathrm{X}$ & \\
\hline $\begin{array}{l}\text { Troca de informação com empresas } \\
\text { (clientes, fornecedores) }\end{array}$ & $\mathrm{X}$ & \\
\hline $\begin{array}{l}\text { Congressos e feiras comerciais e } \\
\text { industriais do setor }\end{array}$ & $\mathrm{X}$ & \\
\hline Sugestões dos empregados & $\mathrm{X}$ & \\
\hline
\end{tabular}

Fonte: Pesquisa de campo.

Quadro 2. Principais formas de desenvolvimento e incorporação de novas tecnologias que a empresa utiliza

\begin{tabular}{|l|c|c|}
\hline \multicolumn{1}{|c|}{ Natureza } & Sim & Não \\
\hline $\begin{array}{l}\text { Cooperação com fornecedor de } \\
\text { equipamento }\end{array}$ & $\mathrm{X}$ & \\
\hline Cooperação com empresa de manutenção & $\mathrm{X}$ & \\
\hline Cooperação com clientes & $\mathrm{X}$ & \\
\hline Cooperação com outras empresas & $\mathrm{X}$ & \\
\hline Cooperação com instituições de ensino & & $\mathrm{X}$ \\
\hline
\end{tabular}

Fonte: Pesquisa de campo.
Outro aspecto importante a ser ressaltado a partir da análise dos Quadros 1 e 2 é que as universidades da região não têm contribuído de forma significativa com a empresa.

Apesar de as entrevistas terem revelado uma forte relação da Comsat com outras empresas, não existe um interesse maior pela parceria com empresas locais, pois a cooperação acontece com empresas de todo o País.

Outra relação interfirmas que acontece se dá por meio de terceirização, que é recorrente na prestação de serviços como limpeza e manutenção da empresa. No caso de projetos e instalação de equipamentos, a terceirização acontece com menor frequência, mas, em todo caso, tem sido essencial porque a empresa pode focar sua atenção em suas principais competências.

Com relação à inserção local da empresa e avaliação da localização, o Quadro 3 especifica as principais vantagens do município. Fica claro que a infraestrutura que é representada pelo Condomínio Tech Town e as facilidades de transportes e comunicação da região são consideradas pontos fortes para a competitividade da empresa. E como essa empresa não mantém nenhum vínculo com universidades, a parceria com instituições de ensino da região de Campinas não caracteriza como uma vantagem. No entanto, a oferta de mão de obra gerada por essas instituições é considerada uma vantagem para a Comsat, assim como os benefícios fiscais concedidos pelo município, como mostrado pelo Quadro 3.

Assim, o que se observa no caso da Comsat é uma inserção na região em busca de vantagens estáticas de localização. Diferente do caso observado na IBM, não parece haver qualquer motivação da empresa na busca de vantagens dinâmicas.

\section{c. Celéstica}

Com o processo de globalização econômica e a preocupação em reduzir custos, toda a produção da empresa localizada no Condomínio Tech Town, assim como em qualquer outra filial em outros países, é orientada e controlada pela matriz. Para

Quadro 3. Vantagens da localização da empresa na região.

\begin{tabular}{|l|c|c|}
\hline \multicolumn{1}{|c|}{ Atributos } & Sim & Não \\
\hline Infraestrutura física disponível & $\mathrm{X}$ & \\
\hline Infraestrutura de serviços disponível & $\mathrm{X}$ & \\
\hline $\begin{array}{l}\text { Proximidade com universidades e centros } \\
\text { de pesquisa }\end{array}$ & & $\mathrm{X}$ \\
\hline Disponibilidade de mão de obra & $\mathrm{X}$ & \\
\hline Qualidade da mão de obra & $\mathrm{X}$ & \\
\hline Incentivos fiscais & $\mathrm{X}$ & \\
\hline Proximidade com fornecedores & & $\mathrm{X}$ \\
\hline Proximidade com o mercado consumidor & & $\mathrm{X}$ \\
\hline Facilidades de comunicação/transporte & $\mathrm{X}$ & \\
\hline
\end{tabular}

Fonte: Pesquisa de campo. 
o Coordenador de P\&D da unidade brasileira, essa iniciativa inibe a duplicidade de esforços na produção entre as diferentes localidades.

Ainda segundo as entrevistas, cerca de $4 \%$ do faturamento da empresa é destinado à $\mathrm{P} \& \mathrm{D}$ na área de TIC, e outro investimento que é realizado está direcionado a treinamentos e cursos oferecidos à gerência e alta direção da empresa.

Com relação ao esforço maior de pesquisa e aprendizado, esse é realizado na matriz e, posteriormente, disseminado entre as unidades, por isso, a principal forma de desenvolvimento e aquisição de novos conhecimentos que Celética de Hortolândia utiliza origina-se da matriz em Toronto.

O Quadro 4 mostra maior detalhamento a respeito de fontes de informação e conhecimentos especializados utilizados pela empresa. Com relação ao Departamento de P\&D, este está localizado na matriz em Toronto, no entanto a unidade de Hortolândia dispõe de um laboratório de engenharia, no qual é criada grande parte das informações e conhecimentos utilizados pela empresa no local.

Outro aspecto importante a ser ressaltado é que, apesar de a empresa possuir um centro de $\mathrm{P} \& \mathrm{D}$ externo,

Quadro 4. Principais fontes de informação/conhecimentos especializados utilizados pela empresa.

\begin{tabular}{|l|c|c|}
\hline \multicolumn{1}{|c|}{ Origem } & Sim & Não \\
\hline Experiências anteriores da equipe & $\mathrm{X}$ & \\
\hline $\begin{array}{l}\text { Departamento de Pesquisa e } \\
\text { Desenvolvimento (P\&D) }\end{array}$ & $\mathrm{X}$ & \\
\hline Consultorias especializadas & & $\mathrm{X}$ \\
\hline Universidades e Centros Tecnológicos & $\mathrm{X}$ & \\
\hline $\begin{array}{l}\text { Publicações especializadas/Catálogos } \\
\text { técnicos }\end{array}$ & & $\mathrm{X}$ \\
\hline Patentes & $\mathrm{X}$ & \\
\hline Aquisição de novos equipamentos & $\mathrm{X}$ & \\
\hline $\begin{array}{l}\text { Troca de informação com empresas } \\
\text { (clientes, fornecedores) }\end{array}$ & $\mathrm{X}$ & \\
\hline $\begin{array}{l}\text { Congressos e feiras comerciais e industriais } \\
\text { do setor }\end{array}$ & $\mathrm{X}$ & \\
\hline Sugestões dos empregados & & \\
\hline
\end{tabular}

Fonte: Pesquisa de campo.

Quadro 5. Principais formas de desenvolvimento e incorporação de novas tecnologias que a empresa utiliza.

\begin{tabular}{|l|c|c|}
\hline \multicolumn{1}{|c|}{ Natureza } & Sim & Não \\
\hline Cooperação com fornecedor de equipamento & $\mathrm{X}$ & \\
\hline Cooperação com empresa de manutenção & & $\mathrm{X}$ \\
\hline Cooperação com clientes & $\mathrm{X}$ & \\
\hline Cooperação com outras empresas & $\mathrm{X}$ & \\
\hline Cooperação com instituições de ensino & $\mathrm{X}$ & \\
\hline
\end{tabular}

Fonte: Pesquisa de campo. ela atribui grande importância ao estabelecimento de parcerias com Universidades e Centros Tecnológicos locais, que é reforçado no Quadro 5, no qual fica clara a cooperação com a universidade.

As entrevistas mostraram que a cooperação com outras empresas é vista como uma forma de desenvolvimento e incorporação de novas tecnologias, no entanto foi dito que ainda falta comprometimento entre as empresas. A Celéstica demonstrou interesse em parcerias com empresas do Tech Town e até mesmo com concorrentes, desde que seja mantido sigilo em determinadas atividades.

A importância da parceria com universidades e centros de pesquisa resultou em vários projetos, entre eles um laboratório no Instituto Eldorado (que é uma OSCIP de consultoria de projetos de pesquisa e desenvolvimento) e outro na Escola Técnica de Campinas do Centro Universitário Salesiano de São Paulo (UNISAL). Esses laboratórios, além de modernos em montagens eletrônicas, visam atender requisitos internacionais de aceitabilidade de montagens eletrônicas. Outro exemplo de parceria com o Instituto Eldorado é o Programa de Capacitação de Recursos Humanos para Projetos de Circuitos Integrados que está relacionado com o Programa Nacional de Microeletrônica do Ministério de Ciência e Tecnologia (MCT). Já em parceria com a Unicamp, foi criado, numa área de $100 \mathrm{~m}^{2}$, um laboratório com recursos para pesquisas em Rádiofrequência.

A avaliação da localização em relação aos aspectos considerados vantajosos para a empresa é evidenciada no Quadro 6.

$\mathrm{O}$ que se pode perceber é que a infraestrutura física e a de serviços foram consideradas vantagens importantes que a empresa buscou ao se instalar no Condomínio Tech Town. Ela buscou também aproveitar as facilidades de transportes e comunicação da região onde o condomínio foi criado.

Apesar de a proximidade com universidades e centros de pesquisa ser considerado um atributo

Quadro 6. Vantagens da localização da empresa na região.

\begin{tabular}{|l|c|c|}
\hline \multicolumn{1}{|c|}{ Atributos } & Sim & Não \\
\hline Infraestrutura física disponível & $\mathrm{X}$ & \\
\hline Infraestrutura de serviços disponível & $\mathrm{X}$ & \\
\hline $\begin{array}{l}\text { Proximidade com universidades e centros } \\
\text { de pesquisa }\end{array}$ & $\mathrm{X}$ & \\
\hline Disponibilidade de mão de obra & & $\mathrm{X}$ \\
\hline Qualidade da mão de obra & $\mathrm{X}$ & \\
\hline Incentivos fiscais & & $\mathrm{X}$ \\
\hline Proximidade com fornecedores & & $\mathrm{X}$ \\
\hline Proximidade com o mercado consumidor & $\mathrm{X}$ & \\
\hline Facilidades de comunicação/transporte & $\mathrm{X}$ & \\
\hline
\end{tabular}

Fonte: Pesquisa de campo. 
vantajoso para a empresa, isso não pode ser caracterizado como uma ativo específico, até porque a empresa construiu outro laboratório fora da região, em parceria com a Universidade de Fortaleza.

Assim, como no caso da IBM, a Celéstica se insere na região em busca de vantagens estáticas e dinâmicas. Porém, também como no caso da IBM, sua política em relação ao local depende da inserção da filial na estratégia global da empresa. Enquanto centro de suporte às operações da América Latina, a filial da IBM de Hortolândia tem todo interesse em capacitar mão de obra para expandir suas operações. Já o que interessa para a estratégia da Celéstica são as atividades de pesquisa e desenvolvimento, que podem ser desenvolvidas no Brasil a custos menores do que em outros países.

\section{Considerações finais}

O Condomínio Tech Town tem contribuído e continuará a contribuir de forma significativa para o aumento da receita do município de Hortolândia, bem como elevar o número de empregos na cidade. Até o momento, este projeto tem caracterizado o município como o mais novo e promissor polo de TIC no País, devido, principalmente, à importância econômica das empresas instaladas no local, como a IBM.

A pesquisa que fundamenta este artigo buscou identificar se a proximidade geográfica das empresas no Condomínio facilitou o estabelecimento de laços de cooperação ou se, no caso destas empresas, o que prevaleceu foi a inserção em redes globais, ou seja, a proximidade organizacional. Como questão associada, buscou-se investigar se a atuação destas empresas na região de Campinas, que se caracteriza pela presença de diversas universidades e centros de pesquisa, favoreceu o desenvolvimento de processos de aprendizado por parte das empresas locais.

No que se refere à questão da proximidade, a análise sugere que cabe separar as relações de cooperação estabelecidas com instituições de ensino e pesquisa das relações de cooperação estabelecidas com empresas. Se a proximidade geográfica favoreceu a aproximação com instituições de ensino e pesquisa, no caso dos laços de cooperação com empresas, a principal motivação é a proximidade organizacional. De fato, a prática de outsourcing por parte das empresas situadas no Condomínio reforça a tendência para um novo modelo de redes flexíveis, o que tende a consolidar de fato a cooperação e troca de conhecimentos entre empresas situadas dentro e fora da região. Como observado por Tigre et al. (2011), o Condomínio Tech Town representa o que os autores chamam de plataforma de outsourcing, ou seja, um cluster de empresas de software e de serviços de informação em que as decisões de localização que atraíram as empresas para o cluster foram fortemente afetadas pelas estratégias das empresas globais deste cluster e pelas vantagens estáticas de localização.

No que se refere à questão associada, a análise dos resultados mostra que as decisões quanto a desenvolvimento de inovações e cooperação com outras empresas e instituições de ensino e pesquisa locais foram motivadas pela situação das filiais das empresas localizadas no Condomínio no cenário global. Assim, a necessidade de mão de obra qualificada e as possíveis reduções de custo advindas de realização de pesquisa e desenvolvimento local levam as empresas a desenvolver laços de cooperação com instituições de ensino e de pesquisa locais. Porém, estes laços de cooperação não necessariamente se traduzem em processos de aprendizado por parte de empresas locais já que a própria IBM absorve o conhecimento que ela gera nas ações de capacitação empregando os egressos das universidades, e a Celéstica não parece priorizar as instituições locais no estabelecimento de laços de cooperação, tendo como critério de seleção de parcerias tecnológicas o escopo das pesquisas.

As entrevistas revelaram ainda que, no que se refere a decisões de localização, as três empresas foram atraídas principalmente por vantagens de localização estáticas, ligadas a infraestrutura, acesso a mercados e mão de obra e incentivos fiscais. No que se refere a vantagens dinâmicas, as entrevistas revelaram que a IBM e a Celéstica usufruem destas vantagens nos limites ditados pela estratégia de suas matrizes.

Apesar da limitação do acesso a algumas empresas, procurou-se entender melhor a relação de parceria entre as empresas do Condomínio e outros atores locais, a partir de reuniões e entrevistas com as autoridades governamentais locais, nas quais foi possível compreender o grau de relacionamento e interesses comuns que existem entre esses atores.

Posto isso, foi observado na pesquisa de campo que, quando houve parcerias entre as empresas do Condomínio, houve certa dificuldade de mantê-las no longo prazo. Portanto, é necessário que exista maior comprometimento entre os parceiros para que o Condomínio se fortaleça enquanto um polo de TIC no município de Hortolândia.

Esta pesquisa nos faz refletir sobre a importância deste tema para futuros trabalhos, como analisar as diferentes estruturas de aglomerações territoriais de modo a estabelecer parâmetros comparativos entre estes sistemas e, por meio disto, verificar as contribuições e principais obstáculos enfrentados pelo governo e empresas na formação de parcerias para consolidação de redes de inovação nos diferentes contextos geográficos, econômicos e políticos. Em outras palavras, são necessários mais trabalhos para qualificar os argumentos de autores como Mendes (2011) quanto às possibilidades de um território promover interações e ganhos de eficiência coletiva. 
Outra questão a ser investigada é de que forma as políticas públicas podem ser articuladas às estratégias empresariais e estimular a capacidade inovadora do território fundamentada na transferência de conhecimento e tecnologia com o objetivo de incrementar a produção de riqueza na região.

\section{Referências}

AMIN, A.; COHENDET, P. Geographies of knowledge formation in firms. Industry and Innovation, v. 12 , n. 4, p. 465-486, Dec 2005. http://dx.doi. org/10.1080/13662710500381658

ASSOCIAÇÃO NACIONAL DE ENTIDADES PROMOTORAS DE EMPREENDIMENTOS INOVADORES - ANPROTEC. Parques Tecnológicos no Brasil: Estudo, Análise e Proposições. Brasília: ANPROTEC, 2006.

BITTENCOURT, E. S. Uma análise das incubadoras de base tecnológica no estímulo ao desenvolvimento local na região metropolitana de Salvador, Bahia. 2008. Dissertação (Mestrado em Engenharia de Produção)-Universidade Federal de Santa Catarina, Florianópolis, 2008.

BRESCHI, S.; MALERBA, F. The Geography of Innovation and Economic Clustering: Some Introductory Notes. Industrial and Corporate Change, v. 10, n. 4, 2001. http://dx.doi.org/10.1093/icc/10.4.817

CASAROTTO FILHO, N.; PIRES, L. H. Redes de pequenas e médias empresas e desenvolvimento local: Estratégias para a conquista da competitividade global com base na experiência Italiana. Atlas, 2001.

CASSIOLATO, J.; SZAPIRO, M. Uma caracterização de arranjos produtivos locais de micro e pequenas empresas. In: LASTRES, H. M. M.; CASSIOLATO, J. E.; MACIEL, M. L. Pequena Empresa: cooperação e desenvolvimento local. Rio de Janeiro: Relume Dumará, 2003. p. 35-50.

CORBETT, M. F. Ten years of outsourcing practice: tactical, strategic, and transformational. 2011. Disponível em: <http://www.outsourcingprofessional. org/firmbuilder>. Acesso em: jul. 2011.

EULALIA, L. A. S.; BREME, C. F.; PIRES, S. R. I. Outsourcing Estratégico como uma prática essencial para uma efetiva Supply Chain Management. ABEPRO, 2011. Disponível em: <http:Ilwww.abepro. org.br>. Acesso em: jul. 2011.

FORAY, D. Characterizing the knowledge base: available and missing indicators. In: ORGANISATION FOR ECONOMIC CO-OPERATION AND DEVELOPMENT - OECD. Knowledge Management in the Learning Society. OECD, 2000. p. 239-255.

GARCIA, S. F. A. et al. Redes interorganizacionais de cooperação para a internacionalização. REGE, v. 17, n. 2, p. 209-224, abr./jun. 2010. http://dx.doi.org/10.5700/ rege 395

GAROFOLI, G. Economic Development, Organization of Production and Territory. Révue d'Économie Industrielle, n. 64, 2 trimestre 1993.

HANSSON, F. Science Parks as knowledge organizations - The 'ba' in action? Department of
Management, Politics and Philosophy, Copenhagen Business School, 2004. Working Paper 15/2004.

INTERNATIONAL BUSINESS MACHINES - IBM. 2009 Disponível em: <www.ibm.com.br $>$.

LA ROVERE, R. L.; CARVALHO, R. L. Cooperação e Desenvolvimento Local. In: CONFERÊNCIA INTERNACIONAL SOBRE EMPREENDEDORISMO - CIPEAL, 3., 2004, Rio de Janeiro. Anais... Rio de Janeiro, 2004. CD-ROM.

LA ROVERE, R. L.; SHEHATA, L. Políticas de Apoio a Micro e Pequenas Empresas e Desenvolvimento Local: Alguns Pontos de Reflexão. Redes, v. 11, n. 3, p. 10-24, set./dez. 2006.

LA ROVERE, R. L.; SHEHATA, L. Políticas de apoio a micro e pequenas empresas e desenvolvimento local: alguns pontos de reflexão. Redes, v. 11, n. 3, set./ dez. 2008

LASTRES, H. M. M.; ARROIO, A.; LEMOS, C. Políticas de apoio a pequenas empresas: do leito de Procusto à promoção de sistemas produtivos locais. In: LASTRES, H. M. M.; CASSIOLATO, J. E.; MACIEL, M. L. Pequena Empresa: cooperação e desenvolvimento local. Rio de Janeiro: Relume Damará, 2003. p. 529-543.

LENGRAND, L.; CHATRIE, I. Business Networks and the Knowledge-Driven Economy. Brussels: European Commission, 1999.

MALMBERG, A.; POWER, D. (How) Do (Firms in) Clusters Create Knowledge? Industry and Innovation, v. 12 , n. 4, p. 409-431, Dec 2005. http://dx.doi. org/10.1080/13662710500381583

MAIS, I. et al. Importância das Redes nos Processos de Inovação e Internacionalização de Empresas de Base Tecnológica. Revista de Administração e Inovação, v. 7, n. 1, p. 41-61, jan./mar. 2010.

MARKUSEN, A. Sticky Places in Slippery Space: a typology of industrial districts. Economic Geography, v. 72 n. 3, jul. 1996. http://dx.doi.org/10.2307/144402

MARTIN, R. L.; SUNLEY, P. Deconstructing Clusters: Chaotic Concept or Policy Panacea? Journal of Economic Geography, v. 3, n. 1, p. 5-35, Jan 2003. http://dx.doi.org/10.1093/jeg/3.1.5

MENDES, A. A. Condomínios Industriais e Empresariais na Região Metropolitana de Campinas, (SP)-Brasil:Avaliação das condições gerais para a reprodução do capital. Revista Geográfica da América Central, p. 1-10, 2011. Número Especial EGAL.

NADVI, K.; SCHMITZ, H. Industrial clusters in less developed countries: review of experiences and research agenda. Brighton: Institute of Development Studies, University of Sussex, 1994. Discussion Paper 339.

PIRES S. R. I. Supply Chain Management. Núcleo de Manufatura Avançada (NUMA - UFSCAR), 2011. Disponível em: <http:॥www.numa.org.br>. Acesso em: jul. 2011.

POMMIER, P. Les Systèmes Productifs Locaux. Paris: DATAR, 2002.

PORTER, M. Clusters and the New Economics of Competition. Havard Business Review, p. 77-90, Nov/Dec 1998.

PYKE, F.; BECATTINI, G.; SENGENBERGER, W. (Ed.). Industrial districts and inter-firm co-operation 
in Italy. Geneva: International Institute for Labour Studies, 1990. 237 p.

RODRIGUES, R. F.; BARBIERO, A. K. M. Interface entre demanda e oferta tecnológicas: a experiência do Conati Tocantins. In: CONGRESSO DA ASSOCIAÇÃO BRASILEIRA DAS INSTITUIÇÕES DE PESQUISA TECNOLÓGICA, 2002, Curitiba. Anais... Curitiba: ABIPTI, 2002.

SIMÕES, J. Chegada da Dell a Hortolândia realça as qualidades da Região Metropolitana de Campinas e o sucesso de política de atração. Campinas: Unicamp, 2006. Inovação Unicamp, edição número 57 - 12,06/2006.

SQUICCIARINI, M. G. Science parks: seedbeds of innovation? A duration analysis of firms' patenting activity. Small Business Economics, v. 32, p. 169-190, 2009. http://dx.doi.org/10.1007/s11187-007-9075-9
SUZIGAN, W. (Coord.). Identificação, Mapeamento e Caracterização Estrutural de Arranjos Produtivos Locais no Brasil. IPEA, out. 2006. Relatório Consolidado.

TIGRE, P. B. et al. Offshore Outsourcing de Software e Serviços: A experiência Brasileira. Rio de Janeiro: IE-UFRJ, 2007. Relatório integrante da pesquisa Indústria Brasileira de Software e Novas Modalidades de Outsourcing Softex, 2007.

TIGRE, P. B. et al. Cidades do Conhecimento: Uma Taxonomia para Analisar Clusters de Software e Serviços. Revista de Administração de Empresas, v. 51, n. 1, p. 15-26, jan./fev. 2011.

YAM, R. C. M. et al. Analysis of sources of innovation, technological innovation capabilities, and performance: An empirical study of Hong Kong manufacturing industries. Research Policy, v. 40, p. 391-402, 2011. http://dx.doi.org/10.1016/j.respol.2010.10.013 